\title{
Ultrasound-guided percutaneous ethanol injection of small and medium-sized thyroid cysts with relatively small amounts of ethanol
}

\author{
Milan Halenka, David Karasek, Zdenek Frysak
}

Background. Ultrasound-guided percutaneous ethanol injection (US-guided PEI) is used in patients with recurring symptomatic thyroid cysts in whom simple drainage was not successful. It is an alternative non-surgical approach in patients refusing or at risk during surgery.

Methods and Results. US-guided PEI was performed in 33 patients, with a success rate of $100 \%$ and significantly decreased cyst volume after 1, 3 and 6 months after the last PEI compared with the initial volume. The mean number of PEl procedures was $1.5 \pm 0.7$ with a mean $96 \%$ ethanol volume of $2.4 \pm 1.2 \mathrm{~mL}$. In the entire group, the initial cyst volume was significantly reduced to the final volume at 6 months after PEI $(10.82 \pm 5.03 \mathrm{~mL}$ vs. $0.78 \pm 0.84 \mathrm{~mL} ; P<0.001)$. Also in all patients, mean volume reduction rates were significantly increased $(P<0.001)$ at check-ups at 1 month $(83.1 \pm 8.1 \%)$, 3 months ( $89.9 \pm 6.3 \%)$ and 6 months $(92.6 \pm 6.4 \%)$. In case of medium-sized cysts, more PEl procedures were needed than in small cysts (1.1 \pm 0.4 vs. $2.0 \pm 0.5)$. The total amount of $96 \%$ ethanol was equal to $22.7 \pm 7.9 \%$ of the initial cyst volume. Conclusion. Our experiences confirm that small and medium-sized cysts may be successfully treated with relatively small amounts of ethanol. In case of medium-sized cysts, more PEl procedures were needed. Final reduction of complex cysts was achieved later. Apart from temporary localized pain, no serious complications were observed in most cases.

Key words: thyroid cyst, ultrasound-guided percutaneous ethanol injection, volume reduction rate

Received: October 3, 2013; Accepted with revision: January 23, 2014; Available online: February 20, 2014 http://dx.doi.org/10.5507/bp.2014.009

Department of Internal Medicine III - Nephrology, Rheumatology and Endocrinology, Faculty of Medicine and Dentistry, Palacky University Olomouc, Czech Republic

Corresponding autor: Milan Halenka, e-mail: milan.halenka@fnol.cz

\section{INTRODUCTION}

The current common availability of ultrasonography has led to an "epidemic" of thyroid nodules with a prevalence of $19-67 \%$, with palpable nodules occurring in $4 \%$ to $7 \%$ of the population ${ }^{1}$. Complex thyroid nodules are due to hemorrhage or degenerative changes, and present in $18-35 \%$ of surgical biopsy specimens ${ }^{2}$. The prevalence of ultrasound detected complex nodules, both palpable and impalpable, is up to $50 \%\left(\right.$ ref. $\left.^{3}\right)$. Complex cysts are defined as cystically degenerated nodules with the cystic component accounting for more than $60 \%$ of the nodule volume 4 . Primary cysts account for approximately $1 \%$ of nodules ${ }^{5,6}$.

Thyroid cysts with a volume of $5 \mathrm{~mL}$ or more may cause mechanical problems and especially cosmetic defects. Simple drainage is usually not successful in either small or medium-sized cysts, with recurrence rates between $58 \%$ and $80 \%$, depending on the size, volume and number of previous aspirations ${ }^{7,8}$. Large complex cysts recur rather commonly ${ }^{9}$.

The basic treatment approach is surgery - partial or total thyroidectomy. However, patients refusing or at risk during surgery may be offered an alternative ethanol sclerotherapy, ultrasound-guided percutaneous ethanol injection (US-guided PEI). This minimally invasive nonsurgical procedure may be indicated in patients with large, solitary or dominant cysts. The mechanism of action of ethanol is based on coagulative necrosis, reactive fibrosis and small vessel thrombosis. Therapeutically successful is a reduction in cyst volume of more than $50 \%$ or complete disappearance of the fluid component and no recurrence of the cyst ${ }^{5,8}$.

Presented here is our experience with US-guided PEI treatment of small and medium-sized cysts using relatively small amounts of $96 \%$ ethanol.

\section{METHODS}

In 2004-2012, US-guided PEI was performed in 33 patients with thyroid cysts ( 26 females, 7 males; mean age $54.2 \pm 14.8$ years; age range $21-79$ years). Therapeutic success was defined as disappearance of the fluid component and no recurrence of the cyst after 1-year follow-up. During regular check-ups, the decrease in cyst volume was measured using the volume reduction rate (VRR) calculated as follows: initial cyst volume - final cyst volume / initial cyst volume $\times 100=$ result $\%\left(\right.$ ref. $\left.{ }^{10}\right)$. The VRR was calculated at 1, 3 and 6 months after the last PEI. A check-up at 12 months was performed to confirm that the cyst did not recur.

The cysts selected for PEI had to be recurrent, symptomatic solitary or dominant (i.e. another small nodule or several other nodules present in the thyroid), with a US-detected volume of $5 \mathrm{~mL}$ or more and the fluid por- 
Table 1. Results of the entire group and individual subgroups.

\begin{tabular}{|c|c|c|c|c|c|}
\hline $\begin{array}{l}\text { Cyst / number } \\
\text { (Number, sex) }\end{array}$ & $\begin{array}{c}\text { All / } 33 \\
(26 \mathrm{~F} / 7 \mathrm{M})\end{array}$ & $\begin{array}{l}\text { Small / } 18 \\
(14 \mathrm{~F} / 4 \mathrm{M})\end{array}$ & $\begin{array}{c}\text { Medium / } 15 \\
(12 \mathrm{~F} / 3 \mathrm{M})\end{array}$ & $\begin{array}{l}\text { Pure / } 11 \\
(9 \mathrm{~F} / 2 \mathrm{M})\end{array}$ & $\begin{array}{c}\text { Complex / } 22 \\
(17 \mathrm{~F} / 5 \mathrm{M})\end{array}$ \\
\hline Age (y) & $54.2 \pm 14.8$ & $52.1 \pm 12.3$ & $56.9 \pm 17.4$ & $45.6 \pm 15.2$ & $58.6 \pm 12.8$ \\
\hline Initial cyst volume (mL) & $10.8 \pm 5.0$ & $6.8 \pm 1.2$ & $15.6 \pm 3.3$ & $10.7 \pm 5.0$ & $10.9 \pm 5.2$ \\
\hline VRR at 1 mo. (\%) & $83.1 \pm 8.1$ & $81.3 \pm 6.3$ & $85.3 \pm 8.4$ & $89.4 \pm 8.0$ & $79.9 \pm 5.2$ \\
\hline VRR at 3 mo. (\%) & $89.9 \pm 6.3^{*}$ & $89.6 \pm 4.6^{*}$ & $90.3 \pm 7.7^{*}$ & $94.3 \pm 4.2^{*}$ & $87.7 \pm 5.9^{*}$ \\
\hline VRR at 6 mo. (\%) & $92.6 \pm 6.4^{*}$ & $93.3 \pm 4.7^{*}$ & $91.8 \pm 7.6^{*}$ & $96.6 \pm 2.9^{*}$ & $90.6 \pm 6.5^{*+}$ \\
\hline Final cyst volume $(\mathrm{mL})$ & $0.8 \pm 0.8^{\S}$ & $0.5 \pm 0.3^{\S}$ & $1.2 \pm 1.0^{\S}$ & $0.3 \pm 0.2^{\S}$ & $1.1 \pm 0.9^{\S}$ \\
\hline PEI $x$ & $1.5 \pm 0.7$ & $1.1 \pm 0.4$ & $2.0 \pm 0.5^{\&}$ & $1.3 \pm 0.5$ & $1.6 \pm 0.7$ \\
\hline Ethanol (mL) & $2.4 \pm 1.2$ & $1.6 \pm 0.6$ & $3.3 \pm 1.1$ & $2.0 \pm 1.0$ & $2.5 \pm 1.2$ \\
\hline Ethanol vs. Initial cyst volume (\%) & $22.7 \pm 7.9$ & $24.1 \pm 9.1$ & $21.0 \pm 5.4$ & $18.9 \pm 4.5$ & $24.5 \pm 8.4$ \\
\hline
\end{tabular}

Cysts: Small (less than $10 \mathrm{~mL}$ ), Medium-sized (more than $10 \mathrm{~mL}$ ), Pure, Complex, VRR - volume reduction rate, PEI x - number of PEI procedures; Significant difference $P<0.05$ at least: ${ }^{*}$ VVR at 3 mo. or VVR at 6 mo. vs. VVR at 1 mo.;

${ }^{+}$VVR at 6 mo. vs. VVR at 3 mo.; ${ }^{\S}$ Final cyst volume vs. Initial cyst volume, ${ }^{\star}$ Medium-sized vs. Small.

tion accounting for at least $70 \%$ of the cyst. They caused mechanical or cosmetic difficulties and recurred after repeated aspirations (complete drainage carried out on at least two occasions previously). In all cases, cytology results were repeatedly benign. The patients, who either refused surgery (mostly younger females) or were at high medical risk during potential surgery, gave informed consent to PEI, the protocol of which was approved by Palacky University Olomouc Ethics Committee.

The initial cyst volume ranged from $5 \mathrm{~mL}$ to $24 \mathrm{~mL}$, with a mean volume of $10.8 \mathrm{~mL}$. Based on both the volume and proportion of the fluid component, the group was subdivided into two pairs of groups to be compared. Eighteen patients had small cysts of up to $10 \mathrm{~mL}(\mathrm{~S}$; range, $5-10 \mathrm{~mL}$ ) and 15 patients had medium-sized cysts of more than $10 \mathrm{~mL}(\mathrm{M}$; range, $10-24 \mathrm{~mL})$. Large cysts (more than $40 \mathrm{~mL}$ ) were not included ${ }^{11}$. Eleven patients had pure $(\mathrm{P})$ cysts, with ultrasound scans showing a cystic component of more than $90 \%$, anechoic content and smooth internal wall; the drained fluid was viscous, clear or pale yellow. Twenty-two patients had complex (C) cysts, with ultrasound scans showing a fluid component of $70-90 \%$ of the volume, anechoic or flocculated contents, roughened wall and septa in some cysts; the aspirated fluid was viscous, dark yellow or brown with detritus (Table 1).

US examinations were carried out using the Philips Sonos 5500 and, from 2011, Philips iU-22 systems and a $10-\mathrm{MHz}$ linear probe. During the procedure, patients were lying in the supine position, with the head slightly tilted back. For cyst aspiration and subsequent PEI, a 20-gauge needle was used. In all cases, the instilled ethanol was not aspirated. First, the cyst was nearly completely drained with only a small amount of the colloid being left to allow visualization of the needle tip. With the needle remaining in the cystic cavity, the aspiration syringe was replaced by a syringe containing $96 \%$ ethanol which was slowly instilled into the collapsed cyst. During a single application, 1-3 mL of ethanol were instilled, an amount equal to approximately $20-30 \%$ of the initial cyst volume. In one case of a medium-sized, rather viscous cyst, only repeated partial drainage could be performed and an 18-gauge needle was used to successfully carry out two-step ethanol ablation $^{12}$. Even in this case, relatively little ethanol was sufficient.

After 1 month, the patients were checked. If US scan revealed fluid formation in the cystic cavity, it was drained and second PEI was performed. If the first PEI was successful, with the cysts not being filled again and only solid, slightly hyperechoic content being observed, US check-ups followed after 3, 6 and 12 months and then once a year (based on the patient's interest). If the second or third PEI had to be carried out, the first check-up was after one month and then the same follow-up pattern was used.

\section{Statistical analysis}

Individual data in the set were not normally distributed. Therefore, to compare changes in the initial cyst volume and VRRs at 1, 3 and 6 months after the last PEI, the Wilcoxon test for paired samples with the Bonferroni correction of significance levels for multiple comparisons were used. To determine possible differences in numbers of PEI procedures in the simple and complex subgroups and in small and medium-sized cysts, Fischer's exact test was used. Spearman's correlation analysis was used to determine relationships between the amount of ethanol used and VRRs in the entire group and in individual subgroups. The level of statistical significance was set at $P<0.05$. 


\section{RESULTS}

In all 33 patients, US-guided PEI with 96\% ethanol was successful and the desired effect was achieved, that is, shrinkage of the cystic cavity and no recurrence during the 6-month follow-up (Fig. 1a,b, 2a,b). The subsequent long-term follow-up, at 1-year intervals, ranged from more than 1 year to 8 years in all patients, with no recurrence of sclerotized cysts in any of them. PEI was performed once in 17 patients (52\%), twice in 14 patients $(42 \%)$ and 3 times in 2 patients (6\%). The mean number of PEI procedures was $1.5 \pm 0,7$ with a mean ethanol volume of $2.4 \pm 1.2$ $\mathrm{mL}$. The total amount of instilled ethanol ranged from 1 $\mathrm{mL}$ to $5 \mathrm{~mL}$, accounting for $13-50 \%$ (mean, $22.7 \pm 7.9 \%$ ) of the initial cyst volume (Table 1).

The entire group had a significant reduction in the initial cyst volume compared with the final volume at 6 months after completion of PEI $(10.82 \pm 5.03 \mathrm{~mL}$ vs. $0.78 \pm 0.84 \mathrm{~mL}, P<0.001$; Fig. $1 \mathrm{a}, \mathrm{b}, 2 \mathrm{a}, \mathrm{b})$. In the entire group (Table 1), there was a significant increase in VRR $(P<0.001)$ at 1 month (range, $70.8-97.1 \%$; mean, $83.1 \pm 8.1 \%$ ), at 3 months (range, $75-98.7 \%$; mean $89.9 \pm 6.3 \%$ ), and at 6 months after the last PEI (range,
75-98.8\%; mean, $92.6 \pm 6.4 \%)$. Moreover, the complex cyst subgroup showed a statistically significant $(P<0.001)$ decrease in cyst volume, or increased VRR even at 6 months as compared with VRR at 3 months (volume at 3 months $1.32 \pm 0.9 \mathrm{~mL}$ vs. volume at 6 months $1.04 \pm 0.91$ $\mathrm{mL}$; VRR at 3 months $87.7 \pm 5.98 \%$ vs. VRR at 6 months $90.6 \pm 6.55 \%$ ). This was not noted in pure cysts. There was no significant difference in the number of PEI procedures between pure and complex cysts. Significantly more PEI procedures $(P<0.001)$ had to be performed in medium-sized cysts as compared with small cysts $(2 \pm 0.52$ vs. $1.06 \pm 0.4)$.

Spearman's correlation analysis of the entire group did not show a significant correlation between the amount of instilled ethanol and VRRs at 1, 3 and 6 months. Only in small cysts with the intial volume of less than $10 \mathrm{~mL}$, there was a significant relationship between the amount of ethanol and VRR at 1 month $(\mathrm{r}=0.700 ; P<0.05)$.

Apart from temporary mild localized pain following application of ethanol, reported by about $30 \%$ of patients and lasting for $8 \mathrm{~h}$ to $24 \mathrm{~h}$ (often as negligible, never as strong), no serious complications were observed. Local anesthesia was not administered.

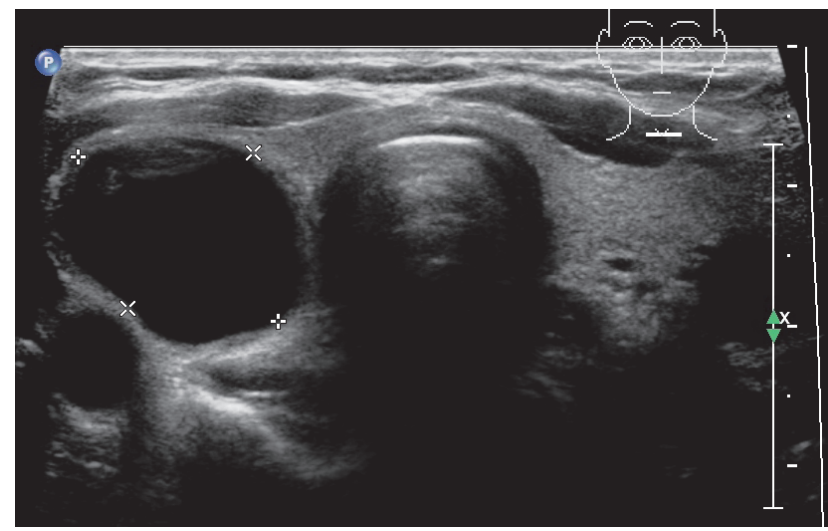

Fig. 1a. Pure cyst $5 \mathrm{~mL}$, before PEI.

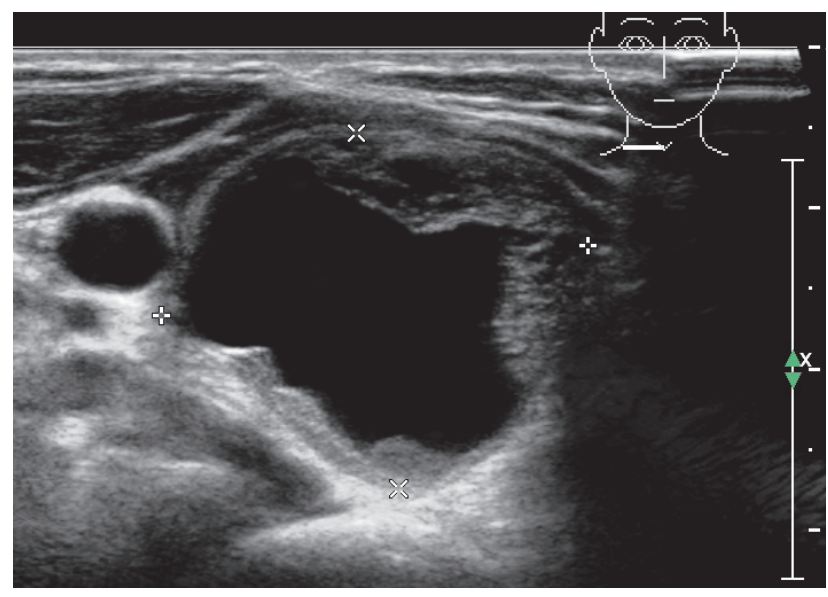

Fig. 2a. Complex cyst $10 \mathrm{~mL}$, before PEI.

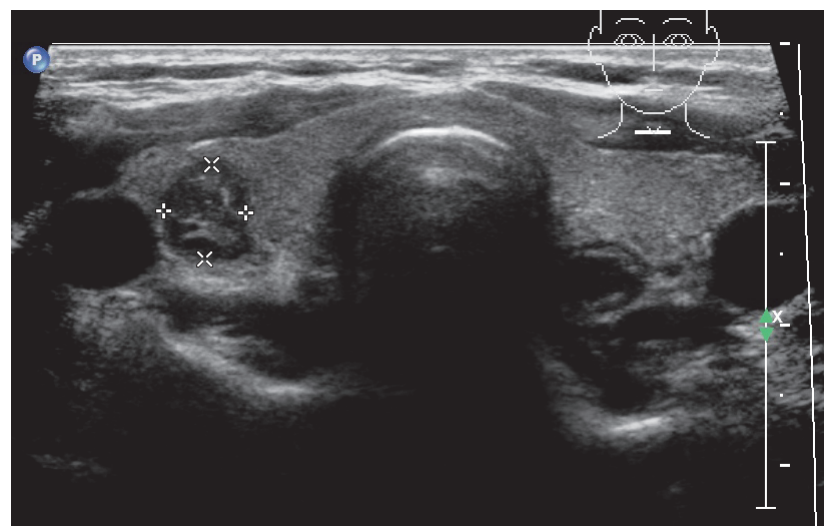

Fig. 1b. Solid residue $0.2 \mathrm{~mL}, 6$ months after one PEI procedure (US transverse).

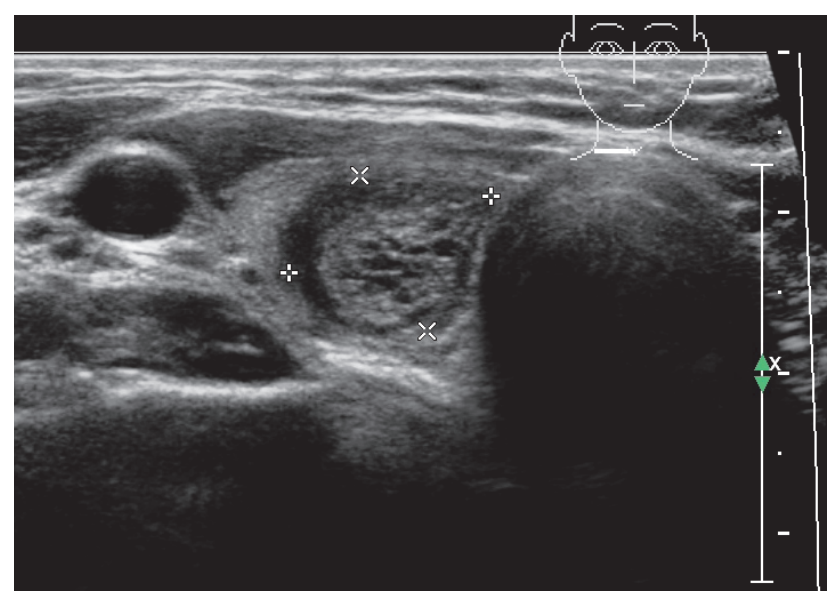

Fig. 2b. Solid residue $0.4 \mathrm{~mL}, 6$ months after two PEI procedures (US transverse). 


\section{DISCUSSION}

Although US-guided PEI is not a method commonly used to treat symptomatic thyroid cysts, it has proven to be a suitable and effective alternative to surgery. A 2013 review by Gharib et al. showed that in large centers with experienced hands, these minimally invasive approaches appear effective and safe and PEI therapy is recommended for recurrent benign thyroid cysts ${ }^{13}$.

In the reported group of small and medium-sized cysts, the success rate was $100 \%$. This may be explained by the selection, with the fluid component being dominant, accounting for more than $70 \%$ of the volume. Complex septated cysts contained only sporadic fine septa; only one cyst had a highly viscous content.

The method is used in two basic modifications. More frequently, a non-aspiration approach is used, that is, the instilled ethanol is left in the cyst. Some authors recommend aspiration of ethanol shortly (2-10 min) after its administration. This procedure is more demanding and usually two injections are required during a session. When comparing the therapeutic success rates in both techniques, the results in the non-aspiration and aspiration groups were similar - $96 \%$ and $93 \%$, respectively ${ }^{14}$. In our group, the non-aspiration approach was used more frequently, both because less ethanol was applied and because the procedure was shorter and another injection was not needed to aspirate ethanol. The reported success rates range from $68 \%$ in a study by Cho et al. to $100 \%$ in a study by Sung et $\mathrm{a}^{15,15}$. In our group, the success rates were identical for both small and medium-sized cysts. In the latter group, however, more PEI procedures had to be carried out.

When comparing pure and complex cysts in our group of patients, the therapeutic goal was achieved in both subgroups. In the pure cyst subgroup, however, final reduction was achieved earlier; in complex cysts, there was a statistically significant increase in VRR at 6 months as compared with VRR at 3 months after PEI. The numbers of PEI procedures were not different in both subgroups. Cho et al. reported no difference in VRRs between pure and complex cysts ${ }^{5}$. For cysts containing thick, viscous fluid, two-step ethanol ablation may be used. First, a small amount of ethanol is injected. This is followed by drainage and PEI procedure 2-4 weeks later ${ }^{12,16}$. This approach was successfully used in one case of a 19-mL cyst in our study. In the management of highly viscous cysts, Sung et al. used one-step ablation, removing the colloid with a catheter connected to a suction pump and then administering ethanol ${ }^{15}$.

The same dosage of ethanol was used for both small and medium-sized cysts in our patients. A significant correlation between the amount of administered ethanol and VRR at 1 month was only found in small cysts with an initial volume of less than $10 \mathrm{~mL}$. Yasuda et al. reported no correlation between the amount of ethanol and VRR, but a lower recurrence rate in such small cysts ${ }^{7}$. Cho et al. found higher VRR in cysts larger than $10 \mathrm{~mL}$ (ref. ${ }^{5}$ ).

From the very beginning, it was our decision to use smaller amounts of ethanol, equal to $22.7 \pm 7.9 \%$ of the initial cyst volume. The reasons were multiple. After nearly complete drainage, the cyst wall collapses, with even smaller amounts of injected ethanol being sufficient to provide its contact with the wall. Little colloid left in the cavity does not dilute the instilled ethanol. Moreover, when using the less frequent ethanol aspiration approach, the ethanol is left in the cavity for 2 to $10 \mathrm{~min}^{8,14,17}$. The amounts of ethanol administered during PEI procedures ranged from $36 \%$ to $100 \%$ of the initial cyst volume in various studies, such as those by Bennedbaek and Hegedüs $36 \%$, Kim YJ et al., Sung et al., Jayesh et al. both $50 \%$, Valcavi et al. $50-70 \%$, Cho et al. $40-100 \%$ or Kim DW et al. $50-100 \%$ (ref. ${ }^{5,8,14,15,18-20}$ ). Although most authors do not recommend to administer a single dose of more than 10 $\mathrm{mL}$ of ethanol, Kim DW et al. injected amounts equal to $100 \%$ of the volume of cysts smaller than $20 \mathrm{~mL}$, that is, up to $20 \mathrm{~mL}$ of absolute ethanol and, in one case of an extremely large $135-\mathrm{mL}$ cyst, even as much as $30 \mathrm{~mL}$ of ethanol ${ }^{14}$

The complications and adverse effects of PEI procedures are caused by ethanol leakage into the surrounding tissues. Most patients report mild, temporary pain at the site of injection, radiating into the neck, chin and ears, due to leakage of a little ethanol into the subcutaneous tissues. In different studies, the pain was reported in $2.5 \%$ to $30 \%$ or, in large cysts, even $70 \%$ of patients ${ }^{14,18,21}$. Occasionally, temporary vocal fold paralysis and dysphonia or, rarely, transient thyrotoxicosis may occur ${ }^{22}$. In the largest set of 432 complex cysts, Lee and Ahn reported transient localized pain in $32(7.9 \%)$ and temporary vocal fold paralysis in only $3(0.7 \%)$ patients ${ }^{10}$. Apart from short-term localized pain, no other complications were noted in our study.

In 2010 Medical Guidelines for Clinical Practice for the Diagnosis and Management of Thyroid Nodules were prepared as a collaborative effort between the American Association of Clinical Endocrinologists (AACE), Associazione Medici Endocrinologi (AME), and European Thyroid Association (ETA). Percutaneous, ultrasound-guided, minimally invasive therapeutic procedures (PEI and percutaneous laser ablation [PLA]) have been proposed for the nonsurgical management of thyroid nodules in selected cases. For cysts and complex nodules with a dominant fluid component PEI is indicated. In other cases, PEI is not indicated for hyperfunctioning nodules or nodular goiters because of a high recurrence rate and the availability of effective alternative treatment options. In solid thyroid nodules that are cold on scintigraphy, clinically significant decreases in nodule size after PEI are reported. The response, however, is less impressive than in cysts, more treatments are needed, and adverse effects are more frequent ${ }^{23}$.

\section{CONCLUSION}

US-guided PEI is an effective alternative to surgery in the treatment of symptomatic and recurring thyroid cysts. Our experiences confirm that small and mediumsized cysts may be successfully treated with relatively 
small amounts of $96 \%$ ethanol equal to $22.7 \pm 7.9 \%$ of the initial cyst volume. In case of medium-sized cysts, more PEI procedures were needed. Final reduction of complex cysts was achieved later. The method is beneficial in that it has a minimum of complications and is performed as an inpatient procedure. The treatment is advised to be carried out in centers with experience in PEI.

\section{ACKNOWLEDGEMENT}

Author contributions: $\mathrm{MH}$ : literature search, manuscript writing, study design, data collection, analysis and interpretation, statistical analysis, figures, final approval; ZF, DK: study design, data analysis and interpretation, statistical analysis, figures, final approval.

Conflict of interest statement: The authors state that there are no conflicts of interest regarding the publication of this article.

\section{REFERENCES}

1. Welker MJ, Orlov D. Thyroid nodules. Am Fam Physician 2003;67(3):559-66.

2. McHenry CR, Slusarczyk SJ, Khiyami A. Recommendations for management of cystic thyroid disease. Surgery 1999;126(6):1167-71.

3. Alexander EK, Heering JP, Benson CB, Frates MC, Doubilet PM, Cibas ES, Marqusee E. Assessment of nondiagnostic ultrasound-guided fine needle aspirations of thyroid nodules. Clin Endocrinol Metab 2002;87(11):4924-7.

4. Kim JH, Lee HK, Lee JH, Ahn IM, Choi CG. Efficacy of sonographically guided percutaneous ethanol injection for treatment of thyroid cysts versus solid thyroid nodules. AJR Am J Roentgenol 2003;180(6):1723-6.

5. Cho YS, Lee HK, Ahn IM, Lim SM, Kim DH, Choi CG, Suh DC Sonographically guided ethanol sclerotherapy for benign thyroid cysts: results in 22 patients. AJR Am J Roentgenol 2000;174(1):213-6.

6. Sheppard MC, Franklyn JA. Management of the single thyroid nodule. Clin Endocrinol 1992;37(5):398-401.

7. Yasuda K, Ozaki O, Sugino K, Yamashita T, Toshima K, Ito K, Harada $\mathrm{T}$. Treatment of cystic lesions of the thyroid by ethanol instillation. World J Surg 1992;16(5):958-61.

8. Bennedbaek FN, Hegedüs L. Treatment of recurrent thyroid cysts with ethanol: a randomized double-blind controlled trial. J Clin Endocrinol Metab 2003;88(12):5773-7.

9. Zingrillo M, Torlontano M, Ghiggi MR, D'Aloiso L, Nirchio V, Bisceglia $M$, Liuzzi A. Percutaneous ethanol injection of large thyroid cystic nodules. Thyroid 1996;6(5):403-8.
10. Lee SJ, Ahn IM. Effectiveness of percutaneous ethanol injection therapy in benign nodular and cystic thyroid diseases: long-term follow-up experience. Endocr J 2005;52(4):455-62.

11. Del Prete S, Caraglia M, Russo D, Vitale G, Giuberti G, Marra M, D'Alessandro AM, Lupoli G, Addeo R, Facchini G, Rossiello R, Abbruzzese A, Capasso E. Percutaneous ethanol injection efficacy in the treatment of large symptomatic thyroid cystic nodules: tenyear follow-up of a large series. Thyroid 2002;12(9):815-21.

12. Zieleźnik W, Kawczyk-Krupka A, Barlik MP, Cebula W, Sieroń A. Modified percutaneous ethanol injection in the treatment of viscous cystic thyroid nodules. Thyroid 2005;15(7):683-6.

13. Gharib H, Hegedüs $L$, Pacella $C M$, Baek JH, Papini E. Clinical review: Nonsurgical, image-guided, minimally invasive therapy for thyroid nodules. J Clin Endocrinol Metab 2013;98(10):3949-57.

14. Kim DW, Rho MH, Kim HJ, Kwon JS, Sung YS, Lee SW. Percutaneous ethanol injection for benign cystic thyroid nodules: is aspiration of ethanol-mixed fluid advantageous? Am J Neuroradiol 2005;26(8):2122-7.

15. Sung JY, Baek JH, Kim YS, Jeong HJ, Kwak MS, Lee D, Moon WJ. One-step ethanol ablation of viscous cystic thyroid nodules. Am J Roentgenol. 2008;191(6):1730-3.

16. Zingrillo M, Torlontano M, Chiarella R, Ghiggi MR, Nirchio V, Bisceglia $M$, Trischitta V. Percutaneous ethanol injection may be a definitive treatment for symptomatic thyroid cystic nodules not treatable by surgery: five-year follow-up study. Thyroid 1999;9(8):763-7.

17. Monzani F, Lippi F, Goletti O, Del Guerra P, Caraccio N, Lippolis PV, Baschieri L, Pinchera A. Percutaneous aspiration and ethanol sclerotherapy for thyroid cysts. J Clin Endocrinol Metab 1994;78(3):800-2.

18. Kim YJ, Baek JH, Ha EJ, Lim HK, Lee JH, Sung JY, Kim JK, Kim TY, Kim WB, Shong YK. Cystic versus predominantly cystic thyroid nodules: efficacy of ethanol ablation and analysis of related factors. Eur Radiol 2012;22(7):1573-8.

19. Jayesh SR, Mehta P, Cherian MP, Ilayaraja V, Gupta P, Venkatesh K. Efficacy and safety of USG-guided ethanol sclerotherapy in cystic thyroid nodules. Indian J Radiol Imaging 2009;19(3):199-202.

20. Valcavi R, Frasoldati A. Ultrasound-guided percutaneous ethanol injection therapy in thyroid cystic nodules. Endocr Pract 2004;10(3):269-75.

21. Verde G, Papini E, Pacella CM, Gallotti C, Delpiano S, Strada S, Fabbrini R, Bizzarri G, Rinaldi R, Panunzi C. Ultrasound guided percutaneous ethanol injection in the treatment of cystic thyroid nodules. Clin Endocrinol 1994;41(6):719-24.

22. Antonelli A, Campatelli A, Di Vito A, Alberti B, Baldi V, Salvioni G, Fallahi P, Baschieri L. Comparison between ethanol sclerotherapy and emptying with injection of saline in treatment of thyroid cysts. Clin Investig 1994;72(12):971-4.

23. Gharib H, Papini E, Paschke R, Duick DS, Valcavi $R$, Hegedüs $L$, Vitti P; AACE/AME/ETA Task Force on Thyroid Nodules. American Association of Clinical Endocrinologists, Associazione Medici Endocrinologi, and EuropeanThyroid Association Medical Guidelines for Clinical Practice for the Diagnosis and Management of Thyroid Nodules. Endocr Pract 2010;16 Suppl 1:1-43. 